$1-1-1989$

\title{
Thermal Sensitivity of Swimming Performance and Muscle Contraction in Northern and Southern Populations of Tree Frogs (Hyla Crucifer)
}

Henry B. John-Adler

M. Christopher Barnhart

Albert F. Bennett

Follow this and additional works at: https://bearworks.missouristate.edu/articles-cnas

\section{Recommended Citation}

John-Alder, Henry B., M. Christopher Barnhart, and Albert F. Bennett. "Thermal sensitivity of swimming performance and muscle contraction in northern and southern populations of tree frogs (Hyla crucifer)." Journal of Experimental Biology 142, no. 1 (1989): 357-372.

This article or document was made available through BearWorks, the institutional repository of Missouri State University. The work contained in it may be protected by copyright and require permission of the copyright holder for reuse or redistribution.

For more information, please contact BearWorks@library.missouristate.edu. 


\title{
THERMAL SENSITIVITY OF SWIMMING PERFORMANCE AND MUSCLE CONTRACTION IN NORTHERN AND SOUTHERN POPULATIONS OF TREE FROGS (HYLA CRUCIFER)
}

\author{
BY HENRY B. JOHN-ALDER \\ Rutgers University, Department of Biological Sciences, \\ Nelson Biological Laboratory, Piscataway, NJ 08855-1059, USA \\ M. CHRISTOPHER BARNHART AND ALBERT F. BENNETT \\ University of California-Irvine, Department of Developmental and Cell Biology, \\ Irvine, CA 92715, USA
}

Accepted 18 October 1988

\begin{abstract}
Summary
The effects of temperature on sprint swimming ability and muscle contractile properties were examined in northern and southern populations of the holarctic tree frog, Hyla crucifer Wied-Neuwied, acclimated to $20-23^{\circ} \mathrm{C}$. Maximal swimming velocities of 29 (southern) and 32 (northern) $\mathrm{cm} \mathrm{s}^{-1}$ and stroke frequencies of $4 \cdot 1$ (southern) and $5 \cdot 5$ (northern) strokes $\mathrm{s}^{-1}$ were attained at $30^{\circ} \mathrm{C}$, and maximal stroke lengths (i.e. distance moved per stroke) of 8.0 (southern) and 7.4 (northern) $\mathrm{cm}$ at $20^{\circ} \mathrm{C}$. The thermal dependence of swimming velocity decreases with increasing temperature (e.g. $Q_{10}=4.0$ from 6 to $10^{\circ} \mathrm{C}, 1.2$ from 20 to $30^{\circ} \mathrm{C}$ ), as reported for locomotion in other ectothermic vertebrates. Over a temperature range of $1 \cdot 5-30^{\circ} \mathrm{C}$, velocity increases by a factor of $5 \cdot 5$, frequency by a factor of 4 , and length by a factor of $1 \cdot 7$. Thus, increased velocity at higher temperatures can be attributed mostly to increased stroke frequency; increments in stroke length contribute less. Muscle contractile properties have similar thermal dependencies to those of other vertebrates: rate processes [including twitch time-to-peak tension (TPT), twitch half-relaxation time $\left(\mathrm{RT}_{1 / 2}\right)$, maximal rate of tetanic tension development and isotonic shortening velocity] are much more sensitive to temperature than is force generation (twitch and tetanic tension). Below $8^{\circ} \mathrm{C}$, stroke frequency is limited by twitch contraction time (TPT $+\mathrm{RT}_{1 / 2}$ ), and leg extension in a swimming stroke by TPT. At higher temperatures, the thermal dependence of stroke time is lower than that of contraction time. Neither locomotor nor muscle contractile properties are different between the two populations (except for twitch tension at low temperatures). Inflexibility in the thermal dependence of muscle contraction and locomotion in this species may help to explain differences in breeding phenologies between northern and southern populations.
\end{abstract}

Key words: amphibian, locomotion, muscle, temperature-dependence, hylidae, population, anuran. 


\section{Introduction}

This study describes and compares the thermal sensitivities of swimming and muscle mechanical performance in northern and southern populations of holarctic tree frogs (Hyla crucifer). We investigated the thermal dependence of swimming locomotion in these frogs and the relationship between muscle contractile performance and limb movements during swimming over a range of temperatures. Finally, we compared the thermal sensitivities of swimming and muscle function in animals from different populations of tree frogs sampled from near the southern limit of their distribution (Conant, 1975) and from a more northern area. We wished to determine whether physiological adaptation to different temperatures in the locomotor apparatus has been an important factor underlying the large distributional range of Hyla crucifer.

Temperature affects the functional properties of skeletal muscles (Bennett, 1984), as it does most biological processes. Consequently, low temperature diminishes an animal's performance in activities such as running (van Berkum, 1986; Huey \& Bennett, 1987) and jumping (John-Alder et al. 1988). In this context, cold animals are at a disadvantage because of reduced locomotor ability. Evolutionary adaptation may partially compensate muscle function for interspecific differences in normal body temperatures (Johnston \& Brill, 1984; JohnAlder \& Bennett, 1987), and cold-tolerant species perform somewhat better at low temperatures than do their warmer counterparts (van Berkum, 1986; Huey \& Bennett, 1987; John-Alder et al. 1988). Such compensation cannot generally be induced by short-term thermal acclimation, at least in amphibians (Putnam \& Bennett, 1981; Renaud \& Stevens, 1981 a,b, 1983a,b; Miller, 1982; Rome, 1983; Miller \& Zoghby, 1986; Else \& Bennett, 1987; Londos \& Brooks, 1988). However, few studies have examined whether populations of a single species differ with regard to locomotor thermal physiology when sampled from different thermal environments within the species' distributional range or at different times of the year (Hertz et al. 1983).

Studies on the thermal dependence of locomotion have also provided insight into functional associations between muscle performance and organismal locomotion. For example, limb cycling during sprint running in lizards is apparently limited by muscle twitch contractile kinetics at low temperatures, whereas at higher temperatures limb movements are less temperature-dependent than is muscle performance (Marsh \& Bennett, 1985, 1986a,b). Marsh \& Bennett (1985, $1986 b$ ) suggested that elastic storage and recovery of energy may help to mitigate the effects of temperature on contractile functions, a mechanism that requires the kinetic and potential energy of an animal's body or of its limbs to be converted to strain energy in the elastic elements of the legs. This conversion might occur in two ways. The first would use the momentum of the body and require contact between an animal and some firm, inertial surface such as the ground. The second would use the momentum of a moving limb and would require that limb movement be essentially unimpeded by the external medium (air or water). Neither seems likel in small animals swimming through water. Thus, we might expect the thermal 
dependencies of time-related muscle functions and limb cycling to be more similar in water than on land. Conversely, a lower temperature-dependence of limb cycling during swimming would suggest a mechanism other than elastic storage and recovery of energy.

Hyla crucifer is abundant and of wide latitudinal distribution in eastern North America. Hedges (1986) places this species in the expanded genus Pseudacris; all species in this genus are early, apparently cold-tolerant, breeders. Our southern population, which is occasionally given separate subspecific status (Conant, 1975), was sampled in Gainesville and Tallahassee, Florida, where breeding typically occurs in January and February. Breeding pairs in this southern population have been found in water at temperatures as low as $12^{\circ} \mathrm{C}$ (J. Travis, personal communication), but minimum field activity temperature may be lower. Our northern population was sampled in Middlesex County, New Jersey. Earliest breeding choruses in this area are heard in the latter half of March, 2 months later than their first appearance in Florida. Individuals in this population are active in water at $8^{\circ} \mathrm{C}$, although breeding pairs are not commonly found below $12^{\circ} \mathrm{C}(\mathrm{P}$. Morin, personal communication).

\section{Materials and methods}

Southern frogs were collected in mid-February and northern frogs in late March 1987. Animals were housed in adjacent aquaria at $20-23^{\circ} \mathrm{C}$ until June. Crickets and Drosophila were available as food at all times. Frogs were observed eating, and faecal pellets accumulated in the aquaria. At dissection, food was found in the frogs' stomachs and all had abdominal fat bodies. Average (mean \pm S.D.) body masses and snout-vent lengths of frogs used for swimming performance were $0.90 \pm 0.217 \mathrm{~g}, 25.9 \pm 1.92 \mathrm{~mm}$ (southern, $N=7$ ) and $0.62 \pm 0.116 \mathrm{~g}$, $22.6 \pm 1.36 \mathrm{~mm}$ (northern, $N=10$ ), and of frogs used for muscle contractile performance $1.10 \pm 0.129 \mathrm{~g}, 26.4 \pm 1.01 \mathrm{~mm}$ (southern, $N=7$ ) and $0.79 \pm 0.081 \mathrm{~g}$, $23.3 \pm 0.88 \mathrm{~mm}$ (northern, $N=7$ ).

\section{Swimming performance}

Swimming performance was analysed at eight temperatures between 1.5 and $30^{\circ} \mathrm{C}$ in a circular tank (radius $75 \mathrm{~cm}$, depth $7 \mathrm{~cm}$ ). The sequence of temperature exposures was randomized. A grid of 5-cm squares was painted on the bottom of the tank, and swimming was filmed with a video camera (Hitachi no. HV-62U) from a height of $1 \mathrm{~m}$. Frogs typically swam just beneath the water surface. Angular distortion was found to be negligible and has been ignored. Frame-by-frame analysis of video tapes provided time resolution of $33 \mathrm{~ms}$.

Swimming trials were made at two temperatures on each of four consecutive days. Body temperatures were adjusted $1 \mathrm{~h}$ prior to swimming trials by placing frogs in boxes containing a small volume of water inside a temperature-controlled abinet. Water temperatures in the swimming tank were maintained within $0.3^{\circ} \mathrm{C}$ of the test temperature. To initiate a trial, an animal was transferred quickly from 
its box into the water above the grid. In most cases, animals immediately began swimming rapidly towards the water's edge. Some animals required prodding at the lowest test temperature.

Single fastest strokes (i.e. strokes of shortest duration) were analysed to emphasize maximal performance levels. ['Stride' is the term analogous to 'stroke' that has been used in discussions of terrestrial running (see below) and fish swimming (see Wardle, 1977); we use 'stroke' because it is defined explicitly in terms of swimming (see Urdang, 1968).] Stroke time was measured as the time required from the onset of leg extension in one stroke until the onset of leg extension in the subsequent stroke. Stroke frequency is the reciprocal of stroke time. Stroke length (i.e. distance moved per stroke) was measured as the distance travelled between the onset of one stroke and the onset of the subsequent stroke. The tip of the frog's snout was used as the point of reference for these distance measurements. Stroke velocity was calculated as stroke length/stroke time. For comparisons between groups, data for each individual were normalized to a maximum of one by dividing all values by the highest in a temperature series, and these normalized values were arcsine-transformed prior to statistical analysis by repeated-measures analysis of variance (ANOVA) (SAS Institute Inc., 1985).

\section{Contractile measurements}

Contractile properties of the isolated plantaris longus (gastrocnemius) muscle, the main extensor of the ankle (Calow \& Alexander, 1973), were measured at a series of 10 temperatures between 0 and $35^{\circ} \mathrm{C}$. The frogs were weighed and measured and then killed by decapitation. Hind limbs were immediately skinned and placed in chilled amphibian Ringer's solution $\left(120 \mathrm{mmoll}^{-1} \mathrm{NaCl}, 2 \mathrm{mmol}^{-1}\right.$ $\mathrm{KCl}, 2 \mathrm{mmoll}^{-1} \mathrm{CaCl}_{2}, 4 \mathrm{mmoll}^{-1}$ Hepes, $10 \mathrm{mmoll}^{-1}$ glucose, $\left.\mathrm{pH} 7 \cdot 2\right)$. The $\mathrm{pH}$ was adjusted at $25^{\circ} \mathrm{C}$. The $\mathrm{pKa}$ of Hepes buffer shifts with temperature by $-0.014 /{ }^{\circ} \mathrm{C}$ (Good et al. 1966), which is similar to the change of arterial $\mathrm{pH}$ with temperature in frogs $\left(-0.016 /{ }^{\circ} \mathrm{C}\right.$ in Rana and Bufo; Howell et al. 1970). Muscle resting length $\left(\mathrm{L}_{0}\right)$ was measured using an ocular micrometer with the thigh and tarsus positioned perpendicular to the shank. The distal tendon was then tied with silk suture and severed from the tarsus, and the tibia and femur were cut at midlength, leaving the muscle attached above the knee. This preparation was mounted in a chamber through which thermostatted Ringer's solution bubbled with $100 \% \mathrm{O}_{2}$ was circulated. The distal tendon was attached via a silver chain to a servo-controlled muscle ergometer (Cambridge Instruments model $300 \mathrm{H}$ ), and the opposite end of the muscle was anchored by tying the attached portions of the femur and tibia firmly to a stainless-steel support.

The muscles were stimulated to contract via two $15 \mathrm{~mm} \times 5 \mathrm{~mm}$ platinum foil electrodes placed near opposite sides of the muscle. Short $(0.2 \mathrm{~ms})$ pulses of current were delivered by a Grass S48 stimulator through a current amplifier. Current and muscle length were adjusted to elicit maximal twitch tension at $20^{\circ} \mathrm{C}$. which indicated depolarization and contraction of all fibres. Tetanic contraction were induced by pulse trains. The pulse frequency and train duration were 
adjusted at each temperature to elicit fused tetanic contraction with a steady plateau of tension; pulse frequency was increased from 30 to $150 \mathrm{~Hz}$ and train duration was decreased from 500 to $100 \mathrm{~ms}$ between 0 and $35^{\circ} \mathrm{C}$. Ergometer output was recorded and analysed using a digital recording oscilloscope (Nicolet model no. 3091).

Isometric and isotonic contractions were recorded first at $20^{\circ} \mathrm{C}$, and then repeated at each of a descending series of temperatures to a minimum of $0^{\circ} \mathrm{C}$. Temperature was then returned to $20^{\circ} \mathrm{C}$, and the contractions repeated as temperature was increased by intervals to $35^{\circ} \mathrm{C}$. Switching temperatures required $10 \mathrm{~min}$ for the small intervals and $30 \mathrm{~min}$ for the increment from 0 to $20^{\circ} \mathrm{C}$. At each temperature the contractile series consisted of an isometric twitch, an isometric tetanus, and an isotonic tetanic contraction with tension set at $50 \%$ of the peak tension recorded in the preceding tetany. Measured variables included peak twitch and tetanic tensions, time-to-peak twitch tension (TPT), time required for twitch half-relaxation $\left(\mathrm{RT}_{1 / 2}\right)$, maximal rate of tetanic tension development, and shortening velocity at $50 \%$ maximal tetanic tension. Our purpose was to compare velocities of muscle shortening between populations, and our standardization of load at $50 \%$ maximal tetanic tension for the isotonic measurements was arbitrary. Maximal power development during isotonic contractions occurs at $40-50 \%$ of maximal tetanic tension in vitro (Marsh \& Bennett, 1985, 1986a; John-Alder \& Bennett, 1987). Typical loading of contractions in vivo is not known. At least $3 \mathrm{~min}$ separated the two tetanic contractions. The full series of measurements required approximately $3 \mathrm{~h}$ for each muscle. Following contractile measurements the muscle was dissected free of bone and tendon and weighed. For comparisons of the two populations of frogs, tensions were normalized to a maximum of 1 , and normalized values were arcsine-transformed prior to repeated-measures ANOVA.

\section{Results}

\section{Swimming performance}

No aspect of swimming performance is statistically distinguishable at the $95 \%$ probability level between animals from northern and southern populations at any temperature (Table 1 ). Similarly, $Q_{10}$ and $R_{10}$ values (the expression $R_{10}$ is analogous to $Q_{10}$ except that it is calculated for biological capacities, such as stroke length, rather than biological rates, such as stroke velocity; see Bennett, 1984) for performance parameters are indistinguishable between groups, with one exception (Table 2). Thus, normalized swimming data and $\mathrm{Q}_{10}$ values have been pooled for an analysis of temperature dependence.

Swimming velocity increases significantly in each temperature interval up to $20^{\circ} \mathrm{C}$, but not from 20 to $30^{\circ} \mathrm{C}$ (Fig. 1). Minimal velocities at $1.5^{\circ} \mathrm{C}$ are about $17 \%$ of maximal.

Stroke frequency is greatest at $30^{\circ} \mathrm{C}$ and falls to about $25 \%$ of maximal at $1.5^{\circ} \mathrm{C}$ Fig. 1). Frequency increases significantly with increasing temperature over most temperature intervals, including that from 20 to $30^{\circ} \mathrm{C}$ where velocity is unchanged. 
Table 1. Swimming velocity, stroke frequency and stroke length (i.e. distance moved per stroke) for northern and southern Hyla crucifer at each test temperature

\begin{tabular}{|c|c|c|c|c|c|c|}
\hline \multirow[b]{2}{*}{$\begin{array}{l}\text { Temperature } \\
\left({ }^{\circ} \mathrm{C}\right)\end{array}$} & \multicolumn{3}{|c|}{ Southern } & \multicolumn{3}{|c|}{ Northern } \\
\hline & $\begin{array}{l}\text { Velocity } \\
\left(\mathrm{cm} \mathrm{s}^{-1}\right)\end{array}$ & $\begin{array}{c}(N=7) \\
\text { Frequency } \\
\left.\text { (strokes s }^{-1}\right)\end{array}$ & $\begin{array}{l}\text { Length } \\
(\mathrm{cm})\end{array}$ & $\begin{array}{l}\text { Velocity } \\
\left(\mathrm{cms}^{-1}\right)\end{array}$ & $\begin{array}{c}(N=10) \\
\text { Frequency } \\
\left.\text { (strokes s }^{-1}\right)\end{array}$ & $\begin{array}{c}\text { Length } \\
(\mathrm{cm})\end{array}$ \\
\hline $1 \cdot 5$ & $5 \cdot 1 \pm 0.57$ & $1 \cdot 0 \pm 0 \cdot 15$ & $4.9 \pm 0.76$ & $5 \cdot 9 \pm 2 \cdot 00$ & $1 \cdot 3 \pm 0 \cdot 20$ & $4.4 \pm 1.25$ \\
\hline $2 \cdot 5$ & $6 \cdot 8 \pm 3 \cdot 87$ & $1 \cdot 2 \pm 0 \cdot 20$ & $5 \cdot 4 \pm 2.65$ & $5 \cdot 2 \pm 1 \cdot 31$ & $1 \cdot 3 \pm 0 \cdot 15$ & $4.1 \pm 0.98$ \\
\hline 4 & $8.9 \pm 2.18$ & $1.4 \pm 0.24$ & $6 \cdot 3 \pm 1 \cdot 52$ & $8 \cdot 6 \pm 1 \cdot 76$ & $2 \cdot 0 \pm 0.09$ & $4.4 \pm 0.78$ \\
\hline 6 & $13 \cdot 1 \pm 5 \cdot 43$ & $2 \cdot 1 \pm 0 \cdot 38$ & $6 \cdot 0 \pm 1 \cdot 81$ & $12 \cdot 3 \pm 3 \cdot 71$ & $2.6 \pm 0.28$ & $4 \cdot 7 \pm 1 \cdot 21$ \\
\hline 10 & $18 \cdot 7 \pm 6 \cdot 12$ & $3 \cdot 0 \pm 0 \cdot 51$ & $6.2 \pm 1.65$ & $17 \cdot 0 \pm 5 \cdot 55$ & $3 \cdot 1 \pm 0.42$ & $5 \cdot 6 \pm 1 \cdot 72$ \\
\hline 15 & $22 \cdot 5 \pm 4 \cdot 26$ & $3 \cdot 2 \pm 0.78$ & $7 \cdot 4 \pm 1 \cdot 91$ & $28 \cdot 3 \pm 8.06$ & $3.9 \pm 0.49$ & $7 \cdot 3 \pm 1 \cdot 96$ \\
\hline 20 & $26 \cdot 4 \pm 10 \cdot 08$ & $3.4 \pm 0.76$ & $8 \cdot 0 \pm 2 \cdot 78$ & $30 \cdot 6 \pm 8 \cdot 60$ & $4 \cdot 1 \pm 0.73$ & $7 \cdot 4 \pm 0 \cdot 98$ \\
\hline 30 & $29 \cdot 0 \pm 11 \cdot 53$ & $4 \cdot 1 \pm 1 \cdot 07$ & $7.5 \pm 3.57$ & $32 \cdot 1 \pm 8.06$ & $5 \cdot 5 \pm 1 \cdot 36$ & $6 \cdot 2 \pm 2 \cdot 00$ \\
\hline
\end{tabular}

There are no significant differences at the $95 \%$ confidence level between populations for any of the performance parameters.

Values are means \pm s.D.

Table 2. Thermal ratios ( $Q_{10}$ and $R_{10}$ values) for parameters of swimming performance calculated over the indicated temperature intervals

\begin{tabular}{cccl}
\hline $\begin{array}{c}\text { Temperature } \\
\text { range }\left({ }^{\circ} \mathrm{C}\right)\end{array}$ & $\begin{array}{c}\mathrm{Q}_{10} \text { of } \\
\text { velocity }\end{array}$ & $\begin{array}{c}\mathrm{Q}_{10} \text { of } \\
\text { frequency }\end{array}$ & $\begin{array}{c}\mathrm{R}_{10} \text { of } \\
\text { length }\end{array}$ \\
\hline $1 \cdot 5-6$ & $10 \cdot 9 \pm 14 \cdot 30^{a}$ & $4 \cdot 9 \pm 1 \cdot 43^{d}$ & $2 \cdot 2 \pm 3 \cdot 02^{a, d}$ \\
$6-10$ & $4 \cdot 0 \pm 6 \cdot 45^{b}$ & $2 \cdot 0 \pm 0 \cdot 78$ & $2 \cdot 2 \pm 3 \cdot 48^{b}$ \\
$10-15$ & $2 \cdot 3 \pm 1 \cdot 15^{c}$ & $1 \cdot 5 \pm 0 \cdot 64^{e}$ & $1 \cdot 8 \pm 1 \cdot 00$ \\
$15-20$ & $1 \cdot 4 \pm 0 \cdot 67$ & $1 \cdot 2 \pm 0 \cdot 43$ & $1 \cdot 2 \pm 0 \cdot 57$ \\
$20-30$ & $1 \cdot 2 \pm 0 \cdot 54^{c}$ & $1 \cdot 4 \pm 0 \cdot 45^{f}$ & $0.9 \pm 0 \cdot 40^{c, f}$
\end{tabular}

Values are means \pm S.D.; these are pooled data $(N=17)$.

Only the values for $\mathrm{Q}_{10}$ of frequency from 6 to $10^{\circ} \mathrm{C}$ were significantly different between populations; northern: $1.6 \pm 0.56$, southern: $2.5 \pm 0.82(P=0.024)$. No other differences between populations were significant at the $95 \%$ confidence level.

Probability levels of the marked comparisons: ${ }^{a} P=0.013 ;{ }^{b} P=0.0319 ;{ }^{c} P=0.0258$; ${ }^{d} P=0.0099 ;{ }^{e} P=0.0053 ;{ }^{f} P=0.0178$.

The $Q_{10}$ values of swimming velocity and stroke frequency are not significantly different except from 10 to $15^{\circ} \mathrm{C}$ (Table 2; $P=0.0053$ ).

Stroke length (i.e. distance moved per stroke) is less temperature-sensitive than velocity or frequency, changing by less than a factor of 2 over the entire temperature range (Fig. 1). Maximal stroke length is attained at $20^{\circ} \mathrm{C}$. The $\mathrm{R}_{10}$ values of stroke length are significantly lower than those of velocity in most temperature intervals (Table 2 ). This comparison just fails to attain significand $(P=0.0767)$ from 10 to $15^{\circ} \mathrm{C}$. The $\mathrm{R}_{10}$ values of stroke length are significantly 


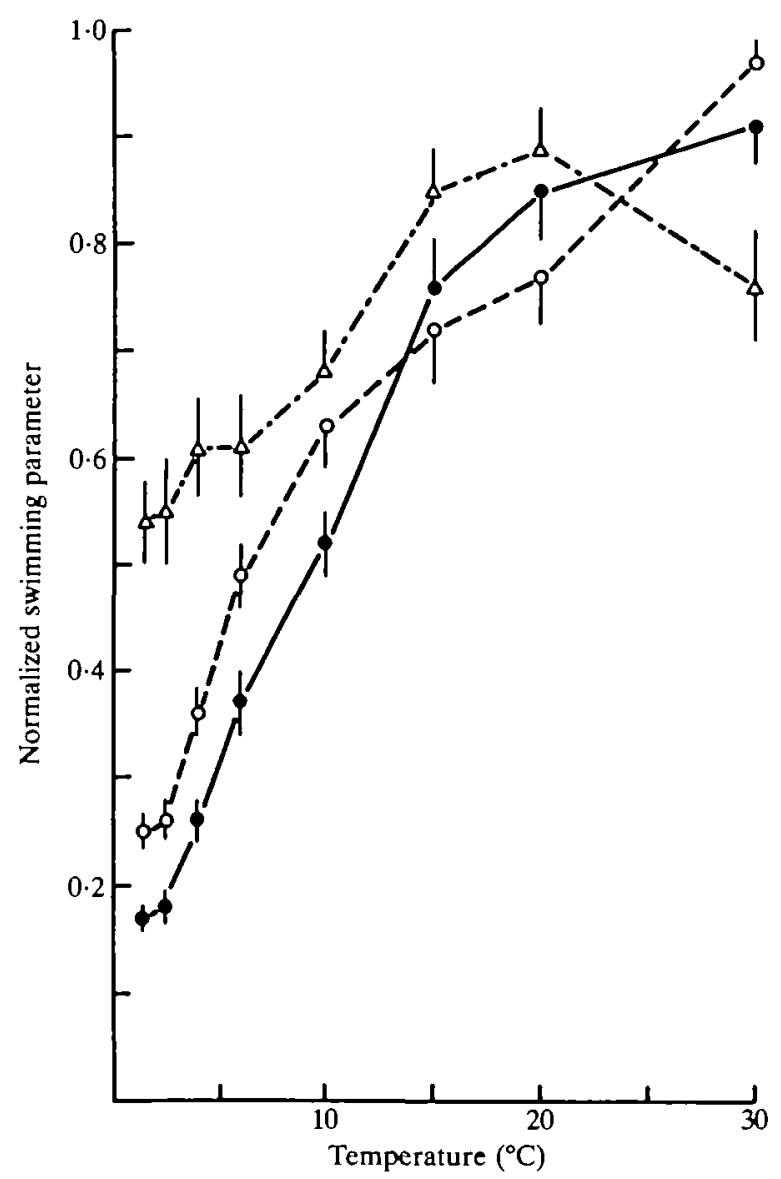

Fig. 1. Normalized swimming velocity $(\odot)$, stroke frequency $(O)$ and stroke length $(\triangle)$ of northern and southern frogs pooled $(N=17)$. Values are means \pm 1 s.E. Paired comparisons were made on arcsine-transformed, normalized values for each performance parameter at consecutive temperatures. Increments in velocity are significant $(P<0.05)$ for all temperature intervals, except from 20 to $30^{\circ} \mathrm{C}$. Increments in frequency are significant for all intervals except from 15 to $20^{\circ} \mathrm{C}$. Changes in length are not significant for any interval except from 10 to $15^{\circ} \mathrm{C}(P=0.006)$.

lower than those of frequency from 1.5 to $6^{\circ} \mathrm{C}(P=0.0099)$ and from 20 to $30^{\circ} \mathrm{C}$ $(P=0 \cdot 0178)$.

\section{Muscle contractile performance}

Contractile properties have nearly identical temperature dependences in the northern and southern populations of Hyla crucifer (Figs 2-4). Only the thermal dependence of twitch tension differs significantly between populations.

Maximal tetanic tensions of about $700 \mathrm{kN} \mathrm{m}^{-2}$ were attained at $15^{\circ} \mathrm{C}$ (Fig. 2A). This high level of tetanic tension can be attributed to our simple calculation of cross-sectional area (volume/length), which underestimates the true fibre cross- 


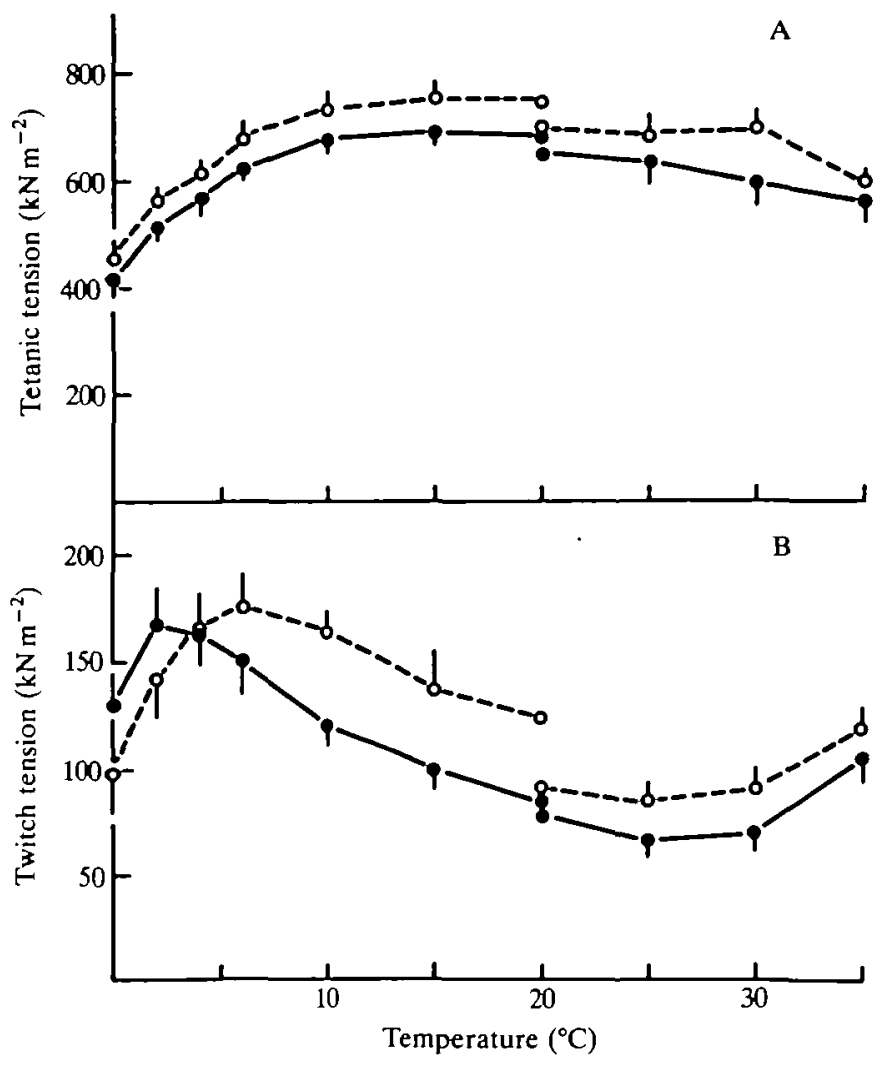

Fig. 2. (A) Tetanic tension as a function of temperature in northern (O) and southern (O) Hyla crucifer. Measurements at $20^{\circ} \mathrm{C}$ were made initially and again after completion of tests at all lower temperatures. Normalized tetanic tension at $30^{\circ} \mathrm{C}$ is significantly greater in southern than in northern frogs $(P=0.036$; repeated-measures ANOVA on arcsine-transformed normalized values). No other differences are significant. (B) Twitch tension vs temperature. Twitch tension is higher in northern frogs at $0(P=0.0023)$ and $2{ }^{\circ} \mathrm{C}(P=0.0001)$ and higher in southern frogs at 20 $(P=0.0244), 25(P=0.0252)$ and $30^{\circ} \mathrm{C}(P=0.0123)$. Statistical analyses were as above.

sectional area of pinnate muscles. If we assume an angle of pinnation of $17^{\circ}$ [the average of three angles measured by Calow \& Alexander (1973) on Rana temporaria], then corrected maximal tetanic tensions are about $205 \mathrm{kN} \mathrm{m}^{-2}$, a reasonable value for vertebrate fast-twitch muscle (McMahon, 1984). Normalized tetanic tension capacities are very similar at most temperatures: only at $30^{\circ} \mathrm{C}$ does the difference between populations attain significance $(P=0.036)$.

Twitch tensions are maximal at a lower temperature in the northern $\left(2^{\circ} \mathrm{C}\right)$ than in the southern $\left(6^{\circ} \mathrm{C}\right)$ frogs (Fig. 2B). Normalized twitch tensions are higher in the northern frogs at $0(P=0.0023)$ and $2^{\circ} \mathrm{C}(P=0.0001)$ and higher in the souther frogs at $20(P=0.0244), 25(P=0.0252)$ and $30^{\circ} \mathrm{C}(P=0.0123)$. This apparent 
Table 3. Thermal ratios $\left(R_{10}\right.$ values) for twitch tension capacities

\begin{tabular}{cccc}
\hline & \multicolumn{2}{c}{ Population } & \\
\cline { 2 - 4 } $\begin{array}{c}\text { Temperature } \\
\text { range }\left({ }^{\circ} \mathrm{C}\right)\end{array}$ & $\begin{array}{c}\text { Southern } \\
(N=7)\end{array}$ & $\begin{array}{c}\text { Northern } \\
(N=7)\end{array}$ & $P$ \\
\hline $0-2$ & $31 \cdot 2 \pm 60 \cdot 06$ & $5 \cdot 7 \pm 6 \cdot 49$ & 0.0584 \\
$2-4$ & $3 \cdot 6 \pm 3 \cdot 62$ & $1 \cdot 1 \pm 0 \cdot 94$ & 0.0007 \\
$4-6$ & $1 \cdot 5 \pm 0 \cdot 79$ & $0 \cdot 7 \pm 0 \cdot 29$ & $0 \cdot 1055$ \\
$6-10$ & $0 \cdot 8 \pm 0 \cdot 08$ & $0 \cdot 6 \pm 0 \cdot 15$ & 0.0159 \\
$10-15$ & $0 \cdot 7 \pm 0 \cdot 14$ & $0 \cdot 7 \pm 0 \cdot 11$ & $0 \cdot 2699$ \\
$15-20$ & $0 \cdot 9 \pm 0 \cdot 28$ & $0 \cdot 7 \pm 0 \cdot 05$ & 0.3479 \\
$20-25$ & $0 \cdot 9 \pm 0 \cdot 31$ & $0 \cdot 7 \pm 0 \cdot 12$ & 0.6010 \\
$25-30$ & $1 \cdot 2 \pm 0 \cdot 24$ & $1 \cdot 1 \pm 0 \cdot 19$ & 0.4157 \\
$30-35$ & $1 \cdot 8 \pm 0 \cdot 57$ & $2 \cdot 3 \pm 0 \cdot 59$ & $0 \cdot 1544$ \\
& & & \\
\hline
\end{tabular}

difference in optimal temperatures for twitch tension is substantiated by comparisons of thermal ratios ( $\mathrm{R}_{10}$ values; Bennett, 1984) (Table 3 ).

Times required for twitch tension development (TPT) do not differ significantly between northern and southern groups at any temperature (Fig. 3A). Similarly, $\mathrm{Q}_{10}$ values for TPT do not differ between groups except from 30 to $35^{\circ} \mathrm{C}$ $(P=0.0008)$. Half-relaxation times $\left(\mathrm{RT}_{1 / 2}\right)$ do not differ between groups at any temperature, and $\mathrm{Q}_{10}$ values for $\mathrm{RT}_{1 / 2}$ differ between groups only from 30 to $35^{\circ} \mathrm{C}$ $(P=0.0461)$.

Maximal rates of tetanic tension development and shortening velocity at $50 \%$ of peak tetanic tension are generally similar in northern and southern groups and are affected in a similar way by temperature (Fig. 4A,B). Only shortening velocity at $25^{\circ} \mathrm{C}$ differs significantly between groups $(P=0.0487)$.

\section{Discussion}

\section{Thermal dependence of swimming locomotion}

Hyla crucifer attain $80 \%$ of maximal swimming velocity at $17 \cdot 2^{\circ} \mathrm{C}$ (interpolated from Fig. 1) and show no further significant improvement from 20 to $30^{\circ} \mathrm{C}$. Temperature coefficients $\left(\mathrm{Q}_{10}\right.$ values $)$ of velocity are high at low temperatures and decrease to about 1 at higher temperatures (Table 2). This pattern of pronounced thermal dependence at low temperatures and near thermal independence at higher temperatures is broadly similar to that of other forms of ectothermic vertebrate locomotion (Miller, 1982; Hertz et al. 1983; Marsh \& Bennett, 1985, 1986b; Stevenson et al. 1985; van Berkum, 1986; Huey \& Bennett, 1987; John-Alder et al. 1988; Londos \& Brooks, 1988).

The thermal dependence of swimming velocity is more similar to that of stroke frequency than to that of stroke length (i.e. distance moved per stroke). Thus, whereas increases in frequency and length both usually contribute to an increase in 

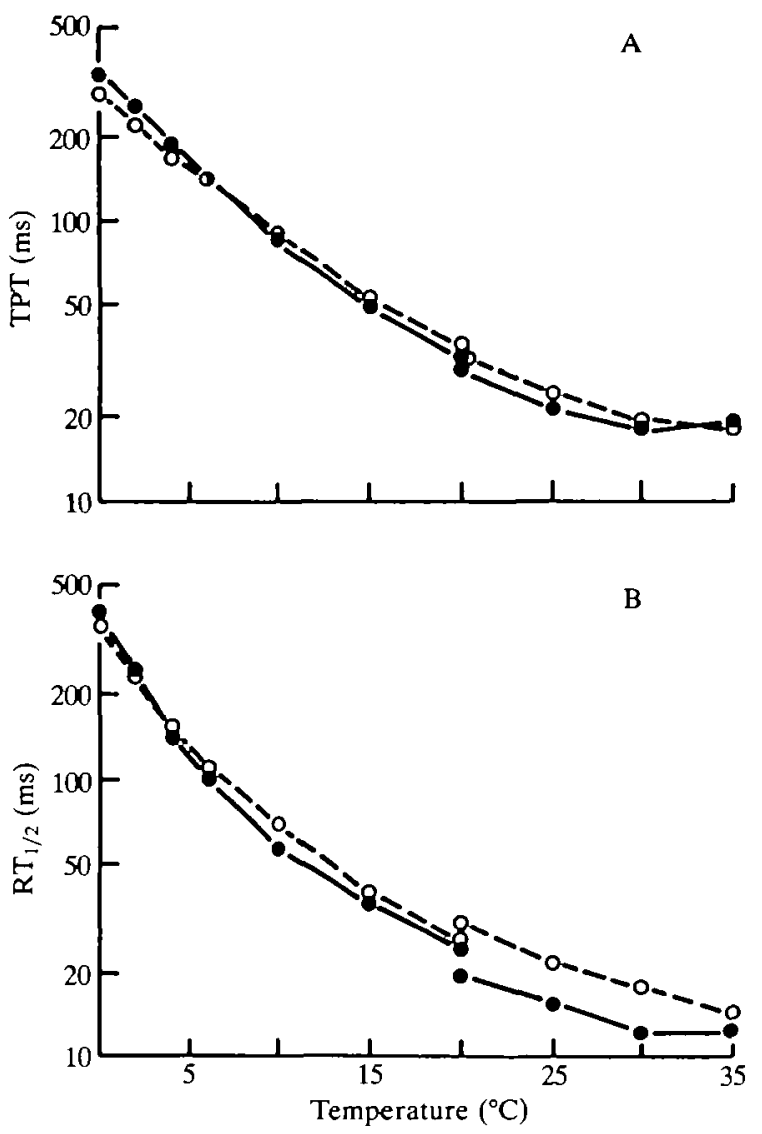

Fig. 3. A. Time-to-peak twitch tension development (TPT) vs temperature for northern $(O)$ and southern $(O)$ tree frogs. There are no significant differences between groups. (B) Half-relaxation time $\left(\mathrm{RT}_{1 / 2}\right)$ vs temperature. There are no significant differences between groups.

velocity, most of this increase can be attributed to frequency. [This conclusion is supported by an analysis of single strokes, as in the present case, and by an analysis of series of three consecutive strokes (not shown).] However, velocity and frequency can change independently. For example, velocity does not increase significantly from 20 to $30^{\circ} \mathrm{C}$ because a significant $21 \%$ increase in frequency is offset by a $17 \%$ decrease in stroke length. Similarly, in a salamander (Ambystoma), swimming velocity does not change from 10 to $20^{\circ} \mathrm{C}$, despite a $10 \%$ increase in tail stroke frequency (Else \& Bennett, 1987), because of an apparent decrease in stroke length. In lizards running on land, stride length is virtually constant over broad ranges of temperature (e.g. $15-40^{\circ} \mathrm{C}$; Marsh \& Bennett, 1985 , $1986 \mathrm{~b}$ ), and sprint velocity varies directly with stride frequency. The differing rold of stride length in swimming and running may be due to frictional drag, which is 

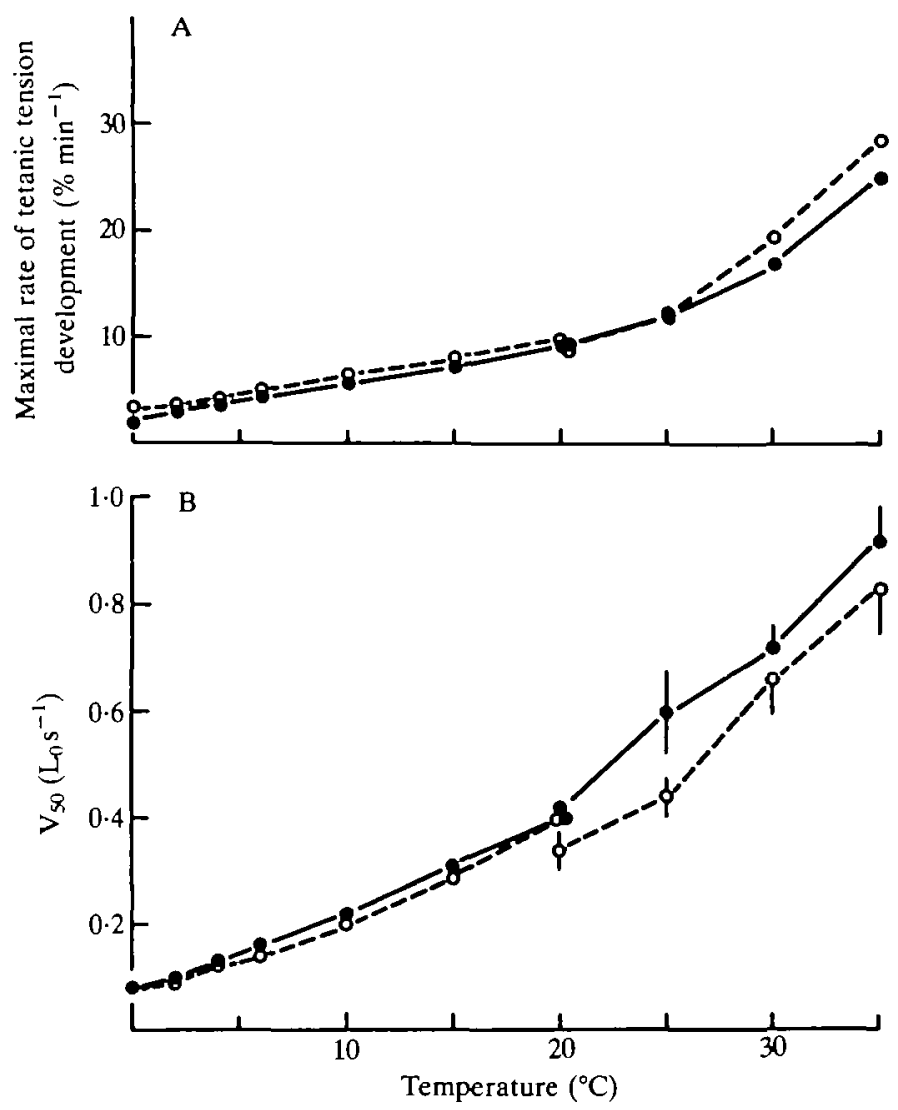

Fig. 4. (A) Maximal rates of tetanic tension development $v s$ temperature. There are no significant differences between northern $(O)$ and southern $(O)$ groups. (B) Isotonic shortening velocity at half-maximal tetanic tension $\left(\mathrm{V}_{50}\right)$ vs temperature. Shortening velocity is greater in northern than in southern frogs at $25^{\circ} \mathrm{C}(P=0 \cdot 0487)$.

important only in water and increases with the square of velocity, thus becoming progressively more significant as animals swim faster.

Temperature effects differ among forms of locomotion, even within a single species. In Hyla crucifer, $80 \%$ of maximal jump distance is attained at about $13^{\circ} \mathrm{C}$ (compared to $17.2^{\circ} \mathrm{C}$ for swimming), and jump distance at $1.5^{\circ} \mathrm{C}$ is still about $45 \%$ of maximal (John-Alder et al. 1988), compared to only $17 \%$ of maximal for swimming velocity. Jumping and swimming are powered by the same major extensor muscles (Calow \& Alexander, 1973). Thus, these differences may stem from the greater involvement of temperature-sensitive, time-related contractile processes in the repeated leg movements of swimming than in the single leg extension of jumping. The differences probably do not result from the fact that Docomotion is on land rather than in water; in contrast to the present observations, terrestrial crawling and walking have higher temperature sensitivities than 
swimming in snakes (Stevenson et al. 1985) and salamanders (Else \& Bennett, 1987), respectively.

\section{Thermal dependence of muscle contractile properties}

The effects of temperature on muscle contractile properties in Hyla crucifer are similar to those seen in other vertebrates (see Bennett, 1984). The remarkable thing about this species is the extent to which its muscles retain force-generating capacity at low temperatures, particularly in comparison to those of lizards (see John-Alder \& Bennett, 1987) and, less strikingly, to those of other amphibians. There is only a $13 \%$ reduction in tetanic tension from 20 to $5^{\circ} \mathrm{C}$ in $\mathrm{H}$. crucifer compared to about $30 \%$ in Rana pipiens, Bufo americanus (Renaud \& Stevens, 1984) and Ambystoma tigrinum (Else \& Bennet, 1987). [Some of the $13 \%$ reduction in tension may be an effect of small changes in the $\mathrm{pH}$ of the bathing solution (Renaud \& Stevens, 1984).] However, the temperature sensitivity of contractile rate functions is quite similar among these species, and there is no indication of optimization of contractile rate functions at low temperatures.

\section{Contractile limitations on swimming performance}

Twitch contraction time, defined here as the sum of TPT and $\mathrm{RT}_{1 / 2}$ and interpreted as an approximation of the duration of the state of activation (see Marsh \& Bennett, 1985), converges with the time required for half a swimming stroke cycle (the time from the onset of leg extension until the onset of active leg flexion) at about $8^{\circ} \mathrm{C}$ in both populations of tree frogs (Fig. 5). Furthermore, because of the unique pattern of leg movements in frog swimming, we are able to resolve the time required just for leg extension (i.e. the propulsive phase of a stroke). From 1.5 to $6^{\circ} \mathrm{C}$, inclusive, leg extension requires about $53 \%$ of the time before the onset of active flexion, and the time required for leg extension converges with TPT at about $8^{\circ} \mathrm{C}$ (Fig. 6). In other words, TPT converges with the time required for about one-quarter of a stroke cycle. Our results extend and strengthen the generality of contractile limitations on leg movements which have previously been reported in lizards and salamanders (Marsh \& Bennett, 1985, 1986; Bennett et al. 1986; Else \& Bennett, 1987).

On the basis of our video analysis and our measurements of twitch kinetics, the time course of leg extensions at low temperatures suggests that these movements may be powered by single twitch contractions. However, three lines of evidence are contradictory. First, Emerson \& de Jongh (1980) reported nearly continuous electromyographic activity in muscles of the iliosacral articulation during the propulsive phase of swimming in three species of frogs (presumably at room temperature). Their observations suggest electrical activity in excess of that required to elicit a twitch response. Second, during avian and mammalian flight, electrical activity begins in wing depressor muscles during the upstroke long before the onset of the downstroke (Hermanson \& Altenbach, 1981, 1985; Dial et al. 1988). A similar pattern of electrical activation of leg extensors during flexion ma occur during frog swimming. Third, shortening-induced relaxation of tension in 
isolated muscles is a well-described phenomenon (Hoyle, 1983). Thus, in vitro contraction times probably substantially overestimate in vivo times and may therefore be misleading with regard to in vivo muscle recruitment. The thermal dependence of electromyographic activity in leg muscles and muscle mechanical function in vivo are two issues badly in need of analysis.

Above $8^{\circ} \mathrm{C}$, limb cycling has a lower thermal dependence than twitch kinetics. We do not have a mechanistic explanation for this observation (but see Cavagna et al. 1985), but elastic storage and recovery of energy are improbable in such small animals swimming in water.

\section{Comparison of thermal sensitivities between populations}

There are few differences in thermal sensitivity between the northern and southern populations, twitch tension at low temperatures being the exception. Although this difference might indicate thermal adaptation of the two populations, it is puzzling that twitch contractile kinetics do not also differ between

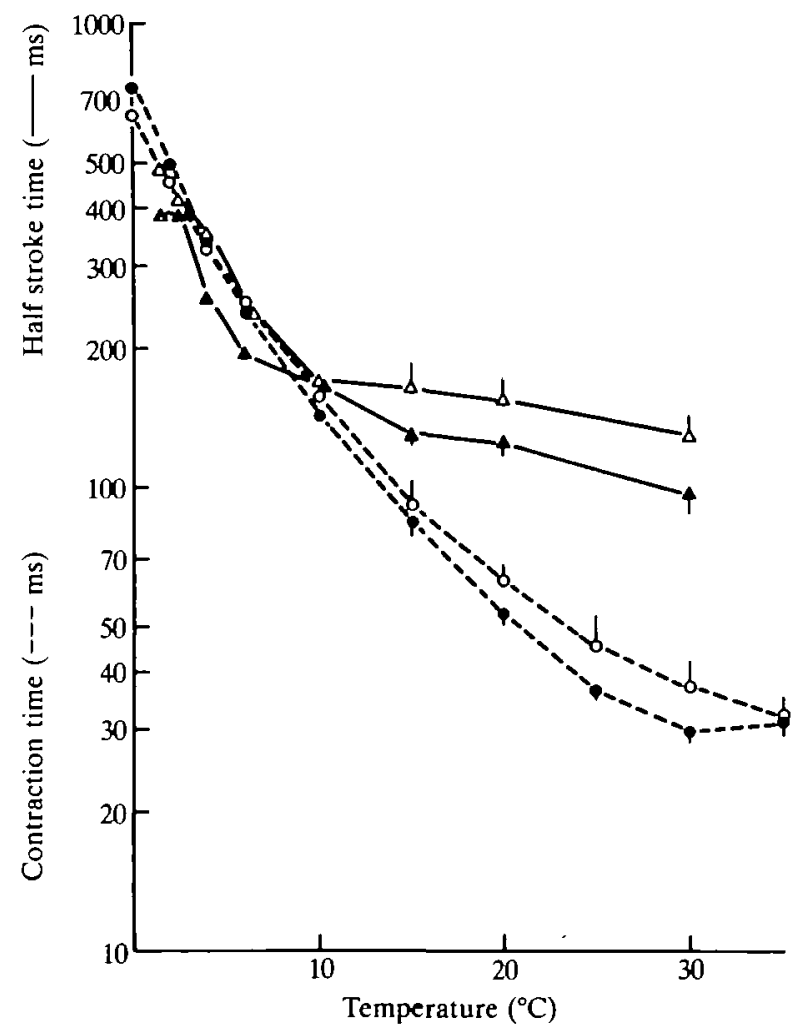

Fig. 5. Contraction time (TPT $+\mathrm{RT}_{1 / 2}$ ) (circles) and half stroke time (triangles) vs temperature. In both groups, these times converge at $7 \cdot 5-8^{\circ} \mathrm{C}$. Below this temperature, leg movement is apparently limited by contraction time; above this temperature, leg movement has a lower thermal dependence than contraction time. Filled symbols, northern frogs; open symbols, southern frogs. 


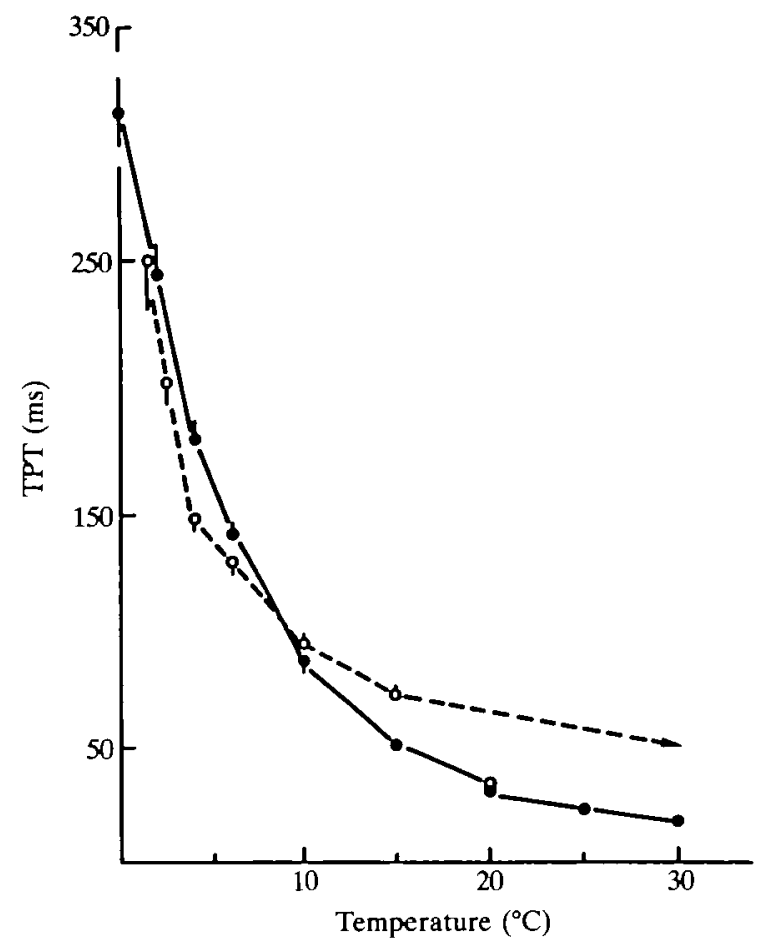

Fig. 6. Time-to-peak twitch tension (O, TPT) and time for leg extension (propulsive phase) $(O)$ vs temperature. Northern and southern data have been pooled to facilitate presentation. These times converge at about $8^{\circ} \mathrm{C}$. Below this temperature, leg extension is apparently limited by TPT. Above $15^{\circ} \mathrm{C}$, uncertainty in the time of leg extension because of the time resolution of the video system is indicated by an arrowhead in place of a fixed symbol.

populations at low temperatures. Furthermore, adaptation in muscle function would probably have been the result of selection on whole-animal locomotion, and we found no differences in swimming capacities at low temperature. Thus, the biological significance of the differences in twitch tension is unclear and perhaps unimportant.

Despite the virtual absence of thermal adaptation within the muscles and locomotor performance of these populations of Hyla crucifer, there is considerable evidence of thermal adaptation among species of tree frogs (John-Alder $e t$ al. 1988). Indices of thermal sensitivity are strongly correlated with minimum field body temperatures, suggesting an important role of thermal physiology in community dynamics. Our present data suggest that thermal physiological factors may contribute to the seasonal differences in breeding activity between northern and southern $H$. crucifer. In both regions, water temperatures are about $12^{\circ} \mathrm{C}$ when breeding activity occurs. In the north, $H$. crucifer breed as early as any other tree frog, whereas in the south they breed later than several species of Pseudacris (P. Morin, personal communication). We suggest that differences in breeding 
phenology between northern and southern populations may be dictated by inflexibility in thermal physiology.

We thank M. Crump at the University of Florida and J. Travis at Florida State University for collecting southern frogs, T. McGuire for loaning his video equipment, A. Glantzman, A. Cruz and P. Shah for helping to measure swimming performance, B. Adams, R. Josephson and J. Malamud for assistance with contractile measurements, K. John-Alder for drawing the figures, and P. Morin and B. Joos for reading an earlier draft. Supported by NSF grant DCB 85-02331 to AFB.

\section{References}

Bennett, A. F. (1984). Thermal dependence of muscle function. Am. J. Physiol. 247, R217-R229.

Bennett, A. F., Huey, R. B. \& John-Alder, H. B. (1986). Body temperature, sprint speed, and muscle contraction kinetics in lizards. Physiologist 29, 179.

Calow, L. J. \& Alexander, R. McN. (1973). A mechanical analysis of a hind leg of a frog (Rana temporaria). J. Zool., Lond. 171, 293-321.

Cavagna, G. A., Mazzanti, M., Heglund, N. C. \& Citterio, G. (1985). Storage and release of mechanical energy by active muscle: a non-elastic mechanism? J. exp. Biol. 115, 79-87.

Conant, R. (1975). A Field Guide to the Reptiles and Amphibians of Eastern and Central North America. Boston, MA: Houghton Mifflin.

Dial, K. P., Kaplan, S. R., Goslow, G. E., JR \& Jenkins, F. A., JR (1988). A functional analysis of the primary upstroke and downstroke muscles in the domestic pigeon (Columba livia) during flight. J. exp. Biol. 134, 1-16.

Else, P. L. \& BENNETT, A. F. (1987). The thermal dependence of locomotor performance and muscle contractile function in the salamander Ambystoma tigrinum nebulosum. J. exp. Biol. 128, 219-234.

EMERSON, S. B. \& DE Jongh, H. J. (1980). Muscle activity at the ilio-sacral articulation of frogs. J. Morph. 166, 129-144.

Good, N. E., Winger, G. D., Winter, W., Connolly, T. N., Izawa, S. \& Singh, R. M. M. (1966). Hydrogen ion buffers for biological research. Biochemistry, N.Y. 5, 467-477.

HEDGES, S. B. (1986). An electrophoretic analysis of Holarctic hylid frog evolution. Syst. Zool. $35,1-21$.

Hermanson, J. W. \& Altenbach, J. S. (1981). Functional anatomy of the primary downstroke muscles in the pallid bat, Antrozous pallidus. J. Mammal. 62, 795-800.

Hermanson, J. W. \& Altenbach, J. S. (1985). Functional anatomy of the shoulder and arm of the fruit-eating bat Artibeus jamaicensis. J. Zool., Lond. 205, 157-177.

Hertz, P. E., Huey, R. B. \& Nevo, E. (1983). Homage to Santa Anita: thermal sensitivity of sprint speed in agamid lizards. Evolution 37, 1075-1084.

Howell, B. J., Baumgardner, F. W., Bonde, K. \& Rahn, H. (1970). Acid-base balance in cold-blooded vertebrates as a function of temperature. Am. J. Physiol. 218, 600-606.

Hoyle, G. (1983). Muscles and Their Neural Control. New York: Wiley.

Huey, R. B. \& Bennetr, A. F. (1987). Phylogenetic studies of coadaptation: preferred temperatures versus optimal performance temperatures of lizards. Evolution 41, 1098-1115.

John-Alder, H. B. \& Bennett, A. F. (1987). Thermal adaptations in lizard muscle function. J. comp. Physiol. B 157, 241-252.

John-Alder, H. B., Morin, P. J. \& LAwLer, S. P. (1988). Thermal physiology, phenology, and distribution of treefrogs. Am. Nat. 132, 506-520.

Johnston, I. A. \& BriLL, R. (1984). Thermal dependence of contractile properties of single skinned muscle fibres from Antarctic and various warm water marine fishes including skipjack tuna (Katsuwonus pelamis) and kawakawa (Euthynnus affinis). J. comp. Physiol. B 155, 63-70. 
Londos, P. L. \& BenneTt, A. F. (1988). Effect of temperature acclimation on locomotory performance curves in the toad, Bufo woodhousii woodhousii. Copeia 1988, 26-32.

McMaron, T. A. (1984). Muscles, Reflexes and Locomotion. Princeton, NJ: Princeton University Press. $277 \mathrm{pp}$.

MARSh, R. L. \& BennetT, A. F. (1985). Thermal dependence of isotonic contractile properties of skeletal muscle and sprint performance in the lizard Dipsosaurus dorsalis. J. comp. Physiol. 155, 541-551.

Marsh, R. L. \& BennetT, A. F. (1986a). Thermal dependence of contractile properties of skeletal muscle from the lizard Sceloporus occidentalis with comments on methods for fitting and comparing force-velocity curves. J. exp. Biol. 126, 63-77.

MARSh, R. L. \& BENNETT, A. F. (1986b). Thermal dependence of sprint performance of the lizard Sceloporus occidentalis. J. exp. Biol. 126, 79-87.

MiLleR, K. (1982). Effect of temperature on sprint performance in the frog Xenopus laevis and the salamander Necturus maculosus. Copeia 1982, 695-698.

MiLLER, K. \& ZoGHBY, G. M. (1986). Thermal acclimation of locomotor performance in anuran amphibians. Can. J. Zool. 64, 1956-1960.

Putnam, R. W. \& BennetT, A. F. (1981). Thermal dependence of behavioural performance of anuran amphibians. Anim. Behav. 29, 502-509.

Renaud, J. M. \& Stevens, E. D. (1981a). The interactive effects of temperature and $\mathrm{pH}$ on the isometric contraction of toad sartorius muscle. J. comp. Physiol. 145, 67-71.

Renaud, J. M. \& Stevens, E. D. (1981 b). Effects of acclimation temperature and $\mathrm{pH}$ on contraction of frog sartorius muscle. Am. J. Physiol. 240, R301-R309.

Renaud, J. M. \& Stevens, E. D. (1983a). The extent of long-term temperature compensation for jumping distance in the frog, Rana pipiens and the toad, Bufo americanus. Can. J. Zool. 61, 1284-1287.

Renaud, J. M. \& Stevens, E. D. (1983b). Effects of step changes in pH on isometric tetanic tension of toad sartorius muscle. Can. J. Physiol. Pharmac. 61, 830-835.

Renaud, J. M. \& Stevens, E. D. (1984). The extent of short-term and long-term compensation to temperature shown by frog and toad sartorius muscle. J. exp. Biol. 108, 57-75.

Rome, L. C. (1983). The effect of long-term exposure to different temperatures on the mechanical performance of frog muscle. Physiol. Zool. 56, 33-40.

SAS InstituTE Inc. (1985) SAS/STAT Guide for Personal Computers, Version 6 Edition. Cary, NC: SAS Institute Inc. 378pp.

Stevenson, R. D., Peterson, C. R. \& Tsusi, J. S. (1985). The thermal dependence of locomotion, tongue flicking, digestion, and oxygen consumption in the wandering garter snake. Physiol. Zool. 58, 46-57.

URDANG, L. (ed.) (1968). The Random House Dictionary of the English Language - College Edition. New York: Random House. 1302pp.

VAN BERKUM, F. H. (1986). Evolutionary patterns of the thermal sensitivity of sprint speed in Anolis lizards. Evolution 40, 594-604.

WardLe, C. S. (1977). Effects of size on the swimming speeds of fish. In Scale Effects in Animal Locomotion (ed. T. J. Pedley), pp. 299-314. New York: Academic Press. 